
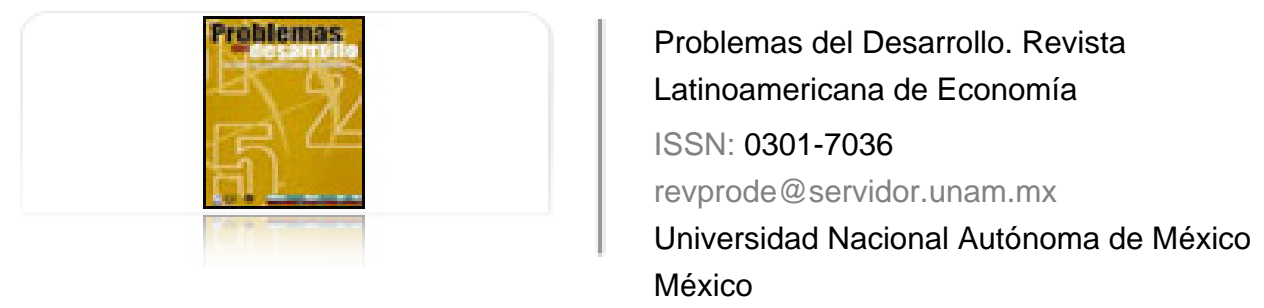

Rosales, Antulio

De la crisis asiática a la crisis inmobiliaria: los debates actuales sobre la arquitectura financiera internacional

Problemas del Desarrollo. Revista Latinoamericana de Economía, vol. 41, núm. 163, octubrediciembre, 2010, pp. 31-51

Universidad Nacional Autónoma de México

Distrito Federal, México

Disponible en: http://www.redalyc.org/articulo.oa?id=11819762003

Cómo citar el artículo

- Número completo

- Más información del artículo

Página de la revista en redalyc.org

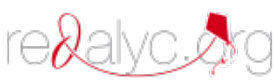

Sistema de Información Científica

Red de Revistas Científicas de América Latina, el Caribe, España y Portugal Proyecto académico sin fines de lucro, desarrollado bajo la iniciativa de acceso abierto 
Revista Problemas del Desarrollo, 163 (41), octubre-diciembre 2010

\title{
DE LA CRISIS ASIÁTICA A LA CRISIS INMOBILIARIA: LOS DEBATES ACTUALES SOBRE LA ARQUITECTURA FINANCIERA INTERNACIONAL
}

\author{
Antulio Rosales*
}

Fecha de recepción: 29 de julio de 2010. Fecha de aceptación: 22 de septiembre de 2010.

\begin{abstract}
Me refiero al desarrollo en los últimos veinte años más o menos, de una superestructura financiera que se encuentra sobre la economía mundial y la mayoría de sus unidades nacionales, siendo ahora relativamente independiente en comparación con años anteriores. Está compuesta de bancos -centrales, regionales y locales-y un grupo de corredores de servicios y títulos financieros descentralizados, todos conectados por una red de mercados, algunos de los cuales están estructurados y son regulados, otros informales y desregulados. Tal entidad es multi-dimensional, y no hay una unidad conceptual que pueda ser utilizada para medir su tamaño.

Paul Sweezy (1994) (traducción propia)
\end{abstract}

\section{RESUMEN}

El proceso de globalización neoliberal ha implicado la propagación de las finanzas internacionales como un mecanismo de acumulación ya no auxiliar a la economía real-productiva, sino como un negocio en sí mismo. La financiarización ha elevado los riesgos y vulnerabilidades de la economía mundial, cada vez más sujetas a crisis. Asimismo, la Arquitectura Financiera Internacional (AFI) se encuentra bajo escrutinio por su cuestionada capacidad para enfrentar tales crisis. Este artículo analiza los debates actuales sobre la reforma de la AFI en el contexto de las crisis financieras de la última década. De la crisis asiática de finales del siglo XX a la crisis inmobiliaria de finales de 2000, el G-20 surge como principal foro político para el avance de reformas y, por otro lado, emergen áreas de influencia regional bajo el liderazgo de potencias emergentes.

\section{PALABRAS CLAVE}

Globalización, crisis financiera, Arquitectura Financiera Internacional, G-20, regionalización.

Profesor e investigador del Centro de Estudios de Economía Política, Universidad Bolivariana de Venezuela. Correo electrónico: antuliorosales@gmail.com. Agradezco los comentarios y sugerencias hechas a versiones previas de este manuscrito por parte de Giuseppe de Corso, Masaya Llavaneras y Elio Córdova, así como a dos árbitros externos. 


\section{Antulio Rosales}

\section{Summary}

The neo-liberal globalization process has meant that the propagation of international finances as a mechanism of accumulation no longer helps the real-productive economy, but has become a business in itself. Financialization has raised the risks and vulnerabilities of the world economy, increasingly subject to crises. Meanwhile, the International Financial Architecture (IFA) is under scrutiny due to its questionable capacity to deal with such crises. This article analyzes the present debates on the reform of the IFA in the context of the financial crises of the last decade. From the Asian crisis at the end of the 20th century to the real estate crisis at the end of first decade of the $21^{\text {st }}$ century, the G-20 emerges as the principal political forum for putting forward reforms. On the other hand, areas of regional influence are emerging under the leadership of emerging powers. Key words: globalization, financial crises, International Financial Architecture, G-20, regionalization.

\section{Résumé}

Le Processus de globalisation néolibérale a impliqué la propagation des finances internationales comme un mécanisme d'accumulation qui n'est plus un auxiliaire de l'économie réelle productive mais un négoce en soi. La financiarisation a élevé les risques et vulnérabilités de l'économie mondiale, toujours plus sujette à des crises. Ainsi, l'Architecture financière internationale (AFI) se trouve sur la sellette pour sa questionnable capacité à faire face à de telles crises. Cet article analyse les débats actuels sur la réforme de l'AFI dans le contexte des crises financières de la dernière décennie. De la crise asiatique de la fin du Xxe siècle à la crise immobilière de la fin des années 2000, le G-20 surgit comme le principal forum politique pour l'avancée de réformes; et d'un autre côté, émergent des aires d'influence régionale sous le leadership de puissances émergentes.

Mots clés : mondialisation, crise financière, Architecture financière internationale, G-20, régionalisation.

\section{Resumo}

O processo de globalizaçáo neoliberal levou à disseminaçáo das finanças internacionais como um mecanismo de acumulaçáo e não como um instrumento auxiliar à economia real-produtiva, mas como um negócio em si mesmo. A financeirização elevou os riscos e vulnerabilidades da economia mundial, cada vez mais sujeita a crises. Além disso, a arquitetura financeira internacional (AFI) está sob exame pela sua questionável habilidade para lidar com tais crises. Este artigo discute os debates atuais sobre a reforma da AFI, no contexto das crises financeiras da década passada. Da crise asiática do final do século Xx à crise imobiliária de finais de 2000, o G-20 surge como o principal fórum político para promover reformas e, por outro lado, emergem zonas de influencia regional sob a liderança de potências emergentes.

Palavras-chave: globalização, crise financeira, arquitetura financeira internacional, G-20, regionalização.

\section{亚洲金融危机，房地产危机：对国际金融体系目前的辩论 综述 \\ 新自由主义全球化进程导致了国际金融作为一种积累机制, 不是帮助生产实体经 济的蔓延, 而当成了独立的独立的商业元素。金融化提高了世界经济的危险度, 越发容易受到危机的袭击。此外, 国际金融架构（AFI）的应付危机的能力正在 审查中。本文讨论在过去十年的金融危机背景下对AFI的改革当前的辩论。从二 十世纪后期的亚洲金融危机到2000年年底的住房危机，20国集团的出现为主要推 进改革, 另一方面, 政治论坛上, 出现了很多由新兴大国领导的, 影响巨大的 新兴地区。 \\ 关键词：全球化，金融危机，国际金融架构，20国集团化，区域化。}




\section{NOTA INTRODUCTORIA LA FINANCIARIZACIÓN, LAS CRISIS Y SU RELACIÓN CON LA AFI}

A finales de la Segunda Guerra Mundial, durante la conferencia de Bretton Woods en 1944, las principales potencias del mundo occidental idearon un conjunto de instituciones que vendrían a regular las relaciones económicas del mundo capitalista de la posguerra. Al Fondo Monetario Internacional (FMI) y al Banco de Reconstrucción y Fomento, denominado después Banco Mundial (BM), se añadieron posteriormente el Acuerdo General de Tarifas - para regular el comercio- y una serie de instituciones crediticias para el desarrollo a escala regional. Este conglomerado de Instituciones Financieras Internacionales (IFIs) ha sido igualmente denominado Arquitectura Financiera Internacional (AFI) en el ámbito económico-político y académico.

No obstante, el devenir histórico de esta Arquitectura Financiera ha implicado profundas transformaciones en su carácter ideológico, programático e incluso técnico. El llamado embedded liberalism de la era keynesiana suponía que estas instituciones servían de palanca económica para que Estados nacionales emprendieran el camino de la industrialización y diversificación económica, mediante la consecución del pleno empleo en sus economías, el mantenimiento de un sistema de tasas de cambio relativamente controladas y un patrón de comercio abierto (Held et al, 2001: 227).

El boom del mercado de divisas de Londres (una grieta en el sistema del control financiero que atraía dólares estadounidenses del bloque socialista en Europa occidental); la transformación en el paradigma tecnológico dominante que reemplazaría con la cibernética e informática la vieja industria fordista metalmecánica y, el proceso de estanflación provocado, entre otros factores, por el aumento de los precios del petróleo, precipitó la rápida desregulación del sistema financiero internacional (Sevares, 2005: 15). Así, el abandono unilateral del patrón dólar-oro a comienzos de la década del setenta del siglo xx por parte de Estados Unidos implicó el fin de la era Bretton Woods, al tiempo que la visión librecambista defendida por economistas neo-clásicos se tornó hegemónica.

El proceso de financiarización económica en el contexto de la globalización es analizado por Paul Sweezy (1994) como un proceso en el cual los principales productores oligopólicos de la segunda mitad del siglo XX obtienen excedentes "mucho más grandes de lo que pueden o quieren consumir”. En ese caso, la propia estructura económica que les provee tal ganancia limita la capacidad de consumo que podría canalizar una inversión posterior para la reproducción del excedente. El propio sistema que contribuía a la generación de la ganancia, limitaba la capacidad de consumo ulterior de la clase trabajadora. El asunto se resuelve con la inversión masiva en propiedad no-productiva, es decir, títulos de valores financieros. Este proceso generó en los años de la estanflación de la década de los setenta del siglo XX una masiva migración de capitales al sector financiero, ya no bajo un principio auxiliar a la economía real-productiva, sino como un negocio en si mismo. Se trata del "triunfo del capital financiero" (Sweezy, 1994). De esta forma, 
la financiarización es una válvula de escape de capitales, pero a su vez de la crisis del régimen de acumulación de la posguerra, que ya mostraba serias grietas.

Wray (2009) basado en el legado de Minsky, la denomina como la fase del capitalismo dominada por los gestores del dinero o money managers. Así, la dinámica de la financiarización del sistema capitalista global ha conllevado a la constitución de "innovaciones" tecnológicas que "han separado riesgo de responsabilidad, contribuyendo al deterioro de la calidad del préstamo y han provocado mayor fragilidad" (Nersisyan y Wray, 2010). Los denominados securities y Credit Default Swaps (CDS) como instrumentos de deuda y riesgo han sido elevados a títulos de valor, ampliando así las actividades financieras de los bancos. De esa manera, la financiarización produjo un sistema de auto-preservación sustentado en las agencias de calificación crediticia y operadores financieros encargados de dar garantías a las nuevas formas de crédito (Wray, 2010). No obstante, Guillén (2009) identifica dos tipos de productos derivados, enfatizando los riesgos que sobrevienen de la "terciarización" de los riesgos con los productos estructurados y derivados de créditos, ya que éstos permiten a los bancos "endosar" el riesgo a un tercero sin perder la titularidad del crédito. En palabras de Guillén (2009):

Los productos derivados de crédito proveen un medio muy apreciado por los bancos para deshacerse de manera discreta de ciertos riesgos, sin comprometer la relación comercial que mantienen con sus mejores prestatarios. Los productos derivados de crédito se clasifican fuera de balance, lo que permite reducir la exigencia de fondos propios.

Otro importante resultado de esta fase del capitalismo financiarizado ha sido una mayor concentración en pocas y más grandes instituciones financieras que, bajo la premisa de ser "demasiado grandes para caer", han incrementado la vulnerabilidad.

Con la desregulación sistemática del sistema financiero a nivel global sobrevino un aumento significativo de la circulación en los flujos de capitales con resultados contradictorios. Por un lado, el mundo asistió al rápido crecimiento de algunas economías emergentes con sustento en la Inversión Extranjera Directa (IED) y, por otro, la dependencia de estos mercados en capital especulativo. Para la década de 2000, la negociación en divisas es $60 \%$ mayor que el comercio internacional de mercancías, el doble que en la década del ochenta del siglo Xx (Sevares, 2005: 13). Las inversiones de portafolio se incrementaron a los países en vías de desarrollo de 3.7 mil millones de dólares en 1990 a 18.5 mil millones en 2001 y alcanzaron 64 mil millones en 2007, mientras que la IED llegaba a poco menos de 600 mil millones de dólares en 2008, cuando en 2001 habían sido 168.2 mil millones de dólares y, a comienzos de los noventa fueron 24 mil millones (Grabel, 2003: 327 y World Bank Data, 2010). Sólo en América Latina y El Caribe, la IED superaba en 2008 los 125 mil millones de dólares (World Bank Data, 2010). En la actualidad, alrededor de un billón ${ }^{1}$ de dólares diarios pueden moverse en mercados especulativos de

Billón en castellano se refiere a millón de millón o trillion en inglés. 
divisas y activos. Además de esto, la dislocación entre producción y especulación es cada vez más apremiante, la relación entre los valores de activos financieros es de 5 a 1 frente al Producto Bruto Mundial (Bleger, 2009). No obstante, el ratio podría ser superior si se consideran datos del Banco Internacional de Pagos según los cuales, en 2009, se negociaron más de 614 billones de dólares en el mercado de derivados incluyendo los títulos over-the-counter o fuera del mercado de bolsas, al tiempo que el PIB mundial fue tan sólo de poco más de 60 billones de dólares en 2008 (World Bank Data, 2010).

La brusca liberalización financiera y la consecuente entrada de capitales en economías de ingreso medio como las latinoamericanas y las asiáticas precipitaron una serie de crisis económicas hacia finales de la década del noventa del siglo XX y comienzos del XXI. Sin embargo, las políticas de liberalización fueron instrumentalizadas y apoyadas desde los Estados industriales del norte y las agencias multilaterales, más allá de un movimiento natural producto de la ampliación tecnológica, tal y como lo plantean los teóricos ortodoxos. Para las agencias multilaterales y gobiernos como el estadounidense, la "plena liberalización de la cuenta de capital ayudaría al más veloz crecimiento de la región” latinoamericana (Stiglitz, 2003: 132). Al contrario, disponer del financiamiento producto de los capitales portafolio somete a las economías a una considerable incertidumbre, que implica una posible variación en la percepción irracional de los inversionistas sobre las economías o una súbita mejora de condiciones para el capital financiero en otros "territorios". Su capacidad para emigrar los capitales de manera masiva e inesperada (tal y como éstos ingresan) representa el principal riesgo para las economías emergentes que no cuentan con sectores financieros "maduros" para enfrentar ataques especulativos o, en última instancia, traducir la entrada rápida de capitales en inversión productiva.

En efecto, la literatura especializada de economía heterodoxa relativa a las causas de la primera ola de crisis financieras en los mercados emergentes a partir de México 1994 hasta Argentina 2001 se enfoca en la "radical liberalización financiera" que asumieron los países latinoamericanos a partir de 1982. Sin embargo, a diferencia de las crisis económicas que tuvieron lugar en las décadas ochenta y noventa del siglo Xx, la más reciente crisis financiera tiene su origen en el centro industrial del mundo capitalista, países cuyos sectores financieros pocos analistas catalogarían como "inmaduros". El estallido de la burbuja inmobiliaria en Estados Unidos ha demostrado serios problemas en la concepción del sistema financiero des-regulado. En primer término, la crisis financiera ha implicado "la generación de ganancias en pocas manos, cuya contrapartida es la inestabilidad y la socialización de las pérdidas cuando se pincha la burbuja" (énfasis propio, Vanoli, 2009). En este caso, el crecimiento del desempleo (que cerró en 10\% en diciembre de 2009 y aún en agosto de 2010 se encontraba en 9.6\%, BLS, 2010), y el estancamiento del consumo son sólo algunas muestras. En segundo lugar, los títulos "basura" (empaquetados con bonos subprime) han provocado incluso la bancarrota de grandes fondos de inversión y aseguradoras en el propio centro financiero globalizado (los quiebres de Lehman Brothers, AIG y la intervención mil millonaria de Fannie Mae y Freddy Mac son evidencia de ello). 
La gravedad de esta crisis afecta no sólo a la ciudadanía estadounidense y sus instituciones financieras sino al entramado institucional de aseguradoras, bolsas, evaluadoras de riesgo y la propia Reserva Federal, que en la lucha por -o contra- la regulación financiera han propiciado serios desequilibrios. La actividad financiera ha ido concentrándose crecientemente en el mercado de derivados, haciéndola dependiente de los valores de los llamados títulos colaterales. De acuerdo con estimados de Nersisyan y Wray (2010), los préstamos industriales y comerciales han decrecido de $20 \%$ a $10 \%$, aproximadamente, desde comienzos de 1990 hasta 2008 en la actividad financiera estadounidense. Entonces, la naturaleza de la inversión bancaria genera dudas sobre la capacidad de los rescates masivos a grandes entidades para impulsar la actividad productiva, ya que estos recursos estarían destinados, en su mayoría, al mercado de derivados y no a la actividad productiva (Nersisyan y Wray, 2010).

Aunque la crisis afecta en gran medida la economía mundial, el contexto actual presenta importantes diferencias respecto a otras crisis financieras para algunas economías emergentes que muestran con fuerza su preponderancia en un eventual nuevo orden internacional. Las economías de gran crecimiento en Asia han servido de prestamistas netos de la economía estadounidense (Salamana, 2008 y Toussaint, 2009), al tiempo que también han generado nuevos flujos financieros con otros países del denominado tercer mundo. En general, la posición de estos últimos es menos vulnerable que en otras ocasiones y ha hecho posible no sólo una mayor capacidad de maniobra de los Estados nacionales frente a la crisis, sino también la apertura a cuestionamientos más profundos del entramado institucional financiero internacional en el marco de los procesos de integración regional.

El objetivo de este artículo es brindar un análisis sobre los principales rasgos de confluencia y divergencia que emergen del debate sobre la AFI en el marco de las pricipales crisis financieras de la última década. Desde la crisis asiática, las voces críticas contra el papel que viene jugando el FMI en las economías emergentes se ha articulado con especial fuerza. Y de la crisis inmobiliaria han surgido con mayor fuerza exigencias para re-regular el sistema financiero, a nivel global o por medio de la regionalización de las finanzas. En efecto, los principales rasgos del actual debate indican el surgimiento de un proceso dual: por un lado, el traslado al G-20 como principal foro político para el avance de propuestas alternativas, no exento de contradicciones y demandas de otros países y factores políticos que pujan por una mayor apertura a la discusión. Por otra parte, surgen áreas de influencia regional en las cuales las potencias emergentes parecieran estar aumentando su poder. Se evidencian ciertos cambios en la formulación de propuestas de reforma en la primera década del siglo XXI. Si bien los cambios en los actores del debate parecieran dar cuenta de una apertura frente a las discusiones de finales de la década del noventa, en la práctica, las propuestas esgrimidas tienden a la reestructuración del sistema liberalizado -con ciertas regulaciones globales- en función del gran capital trasnacional.

Este trabajo trata de articular algunas propuestas relevantes que, partiendo de las crisis financieras de la última década, han sido debatidas a nivel global sobre la AFI. En primer lugar, se analizan las propuestas de la Comisión Meltzer y Anne Krueger sobre el 
futuro de las instituciones de Bretton Woods. Posteriormente, se indaga sobre la idea de la regionalización financiera que surge con la crisis asiática. Para finalizar, se analizan los nuevos aportes del debate establecido por el G-20 y la ONU acerca de la AFI, luego de la crisis inmobiliaria que estalló en Estados Unidos a partir de 2007.

\section{MELTZER Y KRUEGER: DIVISIÓN DEL TRABAJO E INSTITUCIONALIZACIÓN DE LA BANCARROTA}

Con el fin de la crisis del sureste asiático, surgen iniciativas de reforma sustancial de la AFI en el seno de las propias instituciones y el gobierno estadounidense. Dos de esas propuestas reciben especial atención a comienzos de la década: una emerge de la Comisión Meltzer (comisión bipartidista del Congreso estadounidense) y el Mecanismo de Reestructuración de Deuda Soberana (SDRM, por sus siglas en inglés) de la vice-directora del FMI, Anne Krueger.

La Comisión Meltzer realizó un diagnóstico de la situación de la AFI y su efectividad para atender los problemas centrales de la economía mundial. Este trabajo arrojó un sólido cuestionamiento, desde una perspectiva económica ortodoxa, al comportamiento del FMI en el contexto de crisis de finales de la década de los noventa. Por un lado, el informe final de la Comisión insiste en poner en tela de juicio los costosos salvatajes y la forma intrusiva de influenciar la política pública de los Estados-nacionales. En síntesis, la Comisión plantea:

El FMI ha dado muy poca atención a mejorar las estructuras financieras de los países en desarrollo y demasiada a costosas operaciones de rescate. Su sistema de manejo de crisis de corto plazo es muy costosa, sus respuestas demasiado lentas, sus consejos frecuentemente incorrectos y sus esfuerzos por influir en la práctica y la política demasiado intrusivas (traducción propia. Meltzer Report, 2000).

Además, plantea que los prestamistas que hacen préstamos riesgosos y compran bonos con altos riesgos "deben aceptar las pérdidas verdaderas, cuando los riesgos se convierten en realidades indeseadas" (Idem).

Para esta Comisión, la labor del FMI debería ser fungir como un cuasi prestamista de última instancia, aunque debe restringirse al apoyo a los miembros para proveer liquidez en el corto plazo y proveer estabilidad en balanzas de pagos. Asimismo, el informe defiende los condicionamientos de apertura comercial e incluso financiera y de cuenta de capitales de la era de los Programas de Ajuste Estructural (PAEs). No obstante, se propone una clara división y organización del trabajo en el ámbito internacional por las principales instituciones de la AFI:

La asistencia y apoyo para reformas institucionales y políticas económicas probas a largo plazo debe ser responsabilidad del Banco Mundial y de los Bancos de Desarrollo Regional. El 
FMI debe dejar los préstamos para asistencia al desarrollo a largo plazo (en África sub-sahariana) y para transformación estructural (países del antiguo bloque socialista). El Programa Fortalecido de Ajuste Estructural y su sucesor, el programa de Reducción de Pobreza y Crecimiento deben ser eliminados. El FMI debe condonar las deudas íntegramente de los países pobres altamente endeudados que implementen estrategias efectivas de desarrollo en conjunto con el Banco Mundial e instituciones regionales de desarrollo (traducción propia, Meltzer Report, 2000).

De esta forma se arguye que el FMI debe restringirse al auxilio macroeconómico de corto plazo de las llamadas economías emergentes, mientras que el BM y los bancos de desarrollo regional, a la reestructuración a largo plazo de los países más pobres. Por ello, el Fondo debe abandonar los préstamos a estos últimos y, simultáneamente, condonar las deudas de los países pobres altamente endeudados (HIPCs), mientras que se eliminan los PAEs y sus diversas versiones posteriores.

El diagnóstico sobre el BM y los bancos de desarrollo regional no es más esperanzador. Como una "gran brecha" se etiqueta la relación entre la retórica del Banco y los logros obtenidos por sus acciones. La Comisión Meltzer estipula que la tarea de reducir la pobreza y promover el desarrollo en los países más pobres no ha sido el principal esfuerzo del BM; por el contrario, $70 \%$ de los préstamos ingresaban al comienzo de la década a 11 países de ingreso medio que gozaban de fácil acceso a recursos financieros privados: "de cuatro a seis de los más rentables prestamistas, todos con fácil acceso al mercado de capitales, reciben la mayoría de los flujos no destinados a ayuda: 90\% en Asia; 80-90\% en África; 75-85\% en América Latina” (Idem). La situación es similar cuando se considera al Banco Interamericano de Desarrollo (BID), puesto que cerca de 50\% de sus préstamos históricos (desde 1961 hasta comienzos del siglo XXI) ha ido a México, Brasil y Argentina, países con relativo fácil acceso al mercado de capitales. No obstante, los países centroamericanos no alcanzan en su conjunto el 10\% de las inversiones, al tiempo que Haití, el país más pobre de la región, tan sólo había recibido el $0.9 \%$ del capital otorgado hasta 2007 desde la creación de la institución (BID, 2007).

Otro asunto crítico que reveló el informe de la Comisión Meltzer es el traslape e interferencia entre las distintas instituciones abocadas a la inversión para el desarrollo. La escasa articulación y colaboración entre instituciones regionales de desarrollo y el BM hacía que algunos esfuerzos se repitieran y otros se dispersaran, mientras que los costos de oportunidad y acción en las políticas concretas se elevaran sustancialmente (Meltzer Report, 2000):

Las instituciones regionales se traslapan con el Banco Mundial en diversas formas. Compiten por fondos de donaciones, clientes y proyectos. Sus oficinas locales se encuentran frecuentemente en las mismas ciudades. Las regionales repiten la estructura organizacional del Banco, que se enfoca en préstamos subsidiados y garantías a gobiernos, créditos sin intereses a los miembros más pobres, y préstamos, garantías y títulos de capitales para el sector privado. 
Recientemente, el Banco Mundial expandió sus oficinas de campo, elevando la duplicación y potencial conflicto con las regionales. La Comisión no recibió una explicación razonable del por qué esta costosa expansión fue escogida, en vez de impulsar mayor cooperación con los bancos de desarrollo regional y confiar el personal de éstos.

Por su parte, la Comisión reportó su preocupación por el seguimiento de las inversiones y la evaluación de proyectos: su mayor énfasis estaba en los resultados (se estima que en el continente africano habría un $73 \%$ de tasa de "fracasos" en los proyectos financiados por las IFIs). Por ello, se recomendó actuar en coordinación entre las instituciones y las comunidades, propiciando mayor participación de estas últimas. Asimismo, los bancos de desarrollo debían concentrarse en los países verdaderamente más pobres y el BM hacerse cargo de África sub-sahariana hasta que el Banco de Desarrollo Africano pudiera asumir un papel protagónico. En general, se esperaba mayor provisión de apoyo técnico para la atracción de inversiones productivas efectivas y una progresiva sustitución de préstamos por ayudas. En ese sentido, los PAEs fueron reemplazados por Papeles de Reducción de la Pobreza (PRP), cuya principal innovación incluía su sometimiento a discusión por la sociedad civil de los países en cuestión. Estos programas se sumaron a la modesta iniciativa de condonación de la deuda para los HIPCs. Los PRP también facilitaban una moderada inversión en el sector educativo e infraestructura, sin embargo, tanto éstos como la iniciativa de condonación de deuda mantenían intactas las condiciones del ajuste estructural.

La Comisión Meltzer discute diversos otros aspectos sobre el funcionamiento de las diversas IFIs en su relación con los Estados soberanos. Un tema que deja abierto es respecto al establecimiento de un mecanismo internacional de reestructuración de deudas. Sobre el particular, la Comisión prefiere "dejar a las partes" - por ahora- las negociaciones de las condiciones de bancarrota, hasta tanto exista una mejor comprensión por parte de deudores, acreedores y observadores de cómo una "intervención del sector público puede mejorar las negociaciones”. Este espacio vacío es el que pretende llenar Anne Krueger con el Sovereign Debt Restructuring Mechanism (SDRM), promovido durante los años 2001 y 2002. El SDRM es uno de los mecanismos propuestos cuyo alcance de reforma a la AFI implicaba una transformación sustancial.

Éste era promovido como un mecanismo para proveer orden, transparencia, predictibilidad al sistema financiero internacional. El SDRM tenía como propósito reducir los costos de las reestructuraciones que resultan de las crisis y default soberanas, tanto para los acreedores como para los deudores (Krueger, 2002). Era, además, un mecanismo legal que implicaba la construcción de una instancia supranacional que se asemejaba a un tribunal de bancarrota, erigido sobre la base de las leyes de bancarrota de países como Estados Unidos. Además del evidente problema de soberanía que este mecanismo implica (las competencias y capacidad de negociación en caso de bancarrota pasarían de los Estados a un tercer ente ajeno a éstos), el SDRM trajo consigo discusiones sobre la acción colectiva de los actores en disputa. 
En términos ideales, este mecanismo debía contribuir a reducir los salvatajes otorgados a los acreedores privados, tal y como ocurrió en México (1995) y el sureste asiático durante la última década del siglo Xx, que produjo desacuerdos en la opinión pública y los gobiernos de distintos países industrializados. En este sentido, se argumenta que los salvatajes "premiaban a los inversionistas por sus pobres decisiones económicas a expensas de los contribuyentes" (Helleiner, 2008). Este argumento, considerado como un moral hazard, fue central a lo largo de las discusiones sobre la reforma de la AFI a comienzos de la década, ya que incluso lo suscribían economistas ortodoxos que, como Eichengreen (2002), consideraban este peligro como una forma de "debilitar al mercado".

El SDRM sería utilizado por los Estados soberanos por solicitud propia, por lo que no sería impuesto desde el FMI, con la intención de que el mecanismo fuera utilizado sólo en casos extremos cuando las partes no puedan arribar a un acuerdo entre ellas (Krueger, 2001). En la práctica, se garantizaría momentáneamente la presencia de los inversionistas en el país reestructurado; se establecería un espacio de negociación formal en el cual el Fondo indicaría políticas públicas para el Estado que resguardarían los intereses de los inversionistas en el proceso de reestructuración durante y posterior al default; y se evitaría la salida abrupta de inversionistas de las negociaciones (Krueger, 2002). Una vez asumido un acuerdo entre una mayoría calificada de inversionistas y el Estado, las "minorías en disenso" deben ajustarse al acuerdo de reestructuración. De esta forma se evita el peligro de polizontes que pretendan alcanzar negociaciones más ventajosas de manera bilateral con los Estados, fuera del mecanismo formal.

La propuesta implicaba una transformación de los artículos constitutivos del Acuerdo del FMI, lo cual exigía la aprobación de tres quintos de sus principales votantes. Los intensos debates suscitados por esta propuesta dividieron a los principales actores pero, en general, hubo recelo con la idea del SDRM. El gobierno estadounidense, si bien a comienzos de 2000 apoyó la idea estatutaria (legal-supranacional), posteriormente se sumaría a los inversionistas privados que defendían una solución contractual. Las Collective Action Clauses (CACs) como parte de los contratos de los bonos internacionales que establecen ciertas condiciones para casos de incumplimiento en los pagos, sería la herramienta preferida por los principales actores privados de la economía financiera:

Los oficiales estadounidenses también estuvieron sometidos a un intenso cabildeo de parte de los representantes de la comunidad financiera internacional. Muchos inversionistas se preocuparon de que las ideas de Krueger aumentarían el poder de los deudores soberanos durante las negociaciones de reestructuración, ya que el FMI no siempre sería un observador desinteresado de la reestructuración de las deudas, dado su propio protagonismo en las deudas soberanas (traducción propia, Helleiner, 2008).

Se sumaron a esta postura los representantes de la Comisión de Finanzas del Congreso estadounidense, lo cual provocó la virtual muerte del SDRM (el apoyo del Congreso era 
central para modificar los estatutos del FMI). Por su parte, los gobiernos de las economías emergentes, los principales Estados "beneficiarios" por este mecanismo, tampoco mostraron mayor apoyo a la idea:

Muchos se mostraron preocupados de ser castigados por los mercados por siquiera expresar apoyo a la propuesta, ya que este apoyo podía ser percibido como un indicador de desear un default. Estos temores sólo se intensificaron cuando la comunidad financiera privada empezó a enfatizar su propia hostilidad hacia la propuesta (traducción propia, Helleiner, 2008).

Estas posiciones congelaron la iniciativa presentada por Krueger. Sin embargo, la experiencia argentina en 2001 demostró que la negociación unilateral y espontánea entre un Estado en situación de bancarrota y los inversionistas privados, sin mediación del FMI, podría suponer riesgosas pérdidas para los acreedores. En este caso, la reestructuración fue acordada, en términos generales, a favor de las condiciones planteadas desde el Estado (el pago prometido rondó el 20\% de la deuda adquirida). Sobre el caso, Helleiner (2008) - un heterodoxo optimista del SDRM- plantea que tal mecanismo "pudo haber llevado a una solución de la crisis más rápida y favorable para los inversionistas e incluso pudo haber minimizado la escala de la crisis en primer lugar". En el lado de la ortodoxia, Eichengreen (2002), sugiere que las CACs en sí mismas no resolverían el problema de vulnerabilidad institucional en caso de default y que la experiencia argentina sentaba un precedente para la adopción de la propuesta de Krueger ya que obligaba negociaciones ordenadas en las cuales Estados e inversionistas debían ceder posiciones.

\section{LA REGIONALIZACIÓN, UNA ALTERNATIVA A LA REFORMA GLOBAL}

Partiendo del debate que suscitaron las propuestas-diagnósticas analizadas precedentemente, una discusión sobre la regionalización de las finanzas vis-à-vis la reforma global tomó lugar durante la primera década del siglo. Después de la crisis especulativa contra el baht tailandés -que se extendió posteriormente a buena parte del emergente sureste asiático-, Japón formuló una propuesta que apuntaba hacia la dirección de la regionalización financiera. Tal iniciativa consistía en aportar 100.000 millones de dólares a un Fondo Monetario Asiático (FMA) que asistiría a las economías inmersas en la crisis y así aplicar medidas expansivas (Stiglitz, 2003: 148). A pesar de haber contado con el apoyo de reconocidos economistas, el gobierno estadounidense y el FMI se opusieron a esta propuesta y contribuyeron a que no se materializara. Stiglitz ironiza al respecto: "el FMI era un fervoroso partidario de la competencia en los mercados, pero rechazaba la competencia en su propio terreno, y eso era el Fondo Monetario Asiático" (Idem). La cooperación regional se mantuvo en el marco de la Iniciativa de Chiang Mai (ICM), donde Japón tuvo un liderazgo sustancial para ayudar a la región a salir de la crisis. 
A partir de 2002, sin embargo, los Estados miembros de la Asociación de Naciones del Sureste Asiático (ASEAN, por sus siglas en inglés) más Japón, la República de Corea y China (ASEAN+3) iniciaron un proceso de swaps o intercambios bilaterales de títulos públicos denominados en monedas locales, con la intención de constituir una canasta de monedas que contribuya a la estabilidad macroeconómica de la región. La ICM produjo hasta 2007 una cesta de reservas por el orden de 80 mil millones de dólares e intercambios bilaterales para mantener el valor de las monedas nacionales (Ugarteche, 2008). En ese momento, comenzó a discutirse la iniciativa de multilateralización del sistema (ICMM), lo que elevaría los swaps bilaterales a un mecanismo regional-multilateral con una institucionalidad propia. Diversas negociaciones sobre la toma de decisiones y los aportes de las partes en lo que sería el primer paso hacia la constitución de un Fondo Monetario. Con la irrupción de la crisis inmobiliaria, este proceso se aceleró y entre los ańos 2009 y 2010 se acordó la institucionalización de un marco multilateral para la ICM que entró en efecto el 24 de marzo de 2010 (ASEAN+3, 2010).

De acuerdo con el convenio suscrito por las partes, la ICMM tiene como propósito: 1) enfrentar dificultades de liquidez en el corto plazo y, 2) complementar a los acuerdos financieros internacionales existentes (énfasis propio, ASEAN+3, 2010). Este logro institucional para la ICM llega no sin problemas entre las partes y, sobre todo, por la rivalidad entre China y Japón, países llamados a ser líderes del mecanismo y de la región. Para Rathus: "tuvo que llegar una amenaza externa encarnada en la Crisis Financiera Global para que Japón y China finalmente bajen sus diferencias y lograr un compromiso en cuanto a contribuciones así como, implícitamente, el peso de los votos" (2010). Además, durante las negociaciones surgieron los ya conocidos debates sobre el uso de las reservas de los Estados, el posible debilitamiento de la soberanía nacional ante amenazas de condiciones en el marco de una nueva supranacionalidad. Eichengreen (2010) lo expone así:

Los principales puntos en debate son las condicionalidades y el pago: los países están renuentes a prestar sus reservas sin garantía de que serán reembolsados, y el pago puede ser esperado con confianza sólo cuando los préstamos son otorgados bajo condiciones. Pero los Estados, a la vez, dudan a la hora de demandar condiciones a sus vecinos ya que eso amenaza las relaciones diplomáticas. El ASEAN+3 enfrentaría este dilema al terciarizar la autoridad de determinar las condiciones y realizar los desembolsos a un consejo de expertos independiente de los gobiernos.

Finalmente, los tres países añadidos a ASEAN, Japón, China y la República de Corea, acordaron aportar un total de 96 mil millones de dólares y el resto de la Asociación aportó 24 mil millones (ASEAN+3, 2010). El mecanismo de votación acordado para temas sustanciales en la ICMM es vía consenso entre los ministros de finanzas y, para los asuntos operativos, por mayoría calificada de dos tercios por representantes nombrados por los Bancos Centrales (o autoridad monetaria en el caso de Hong Kong) y los ministros 
de finanzas. En la negociación de swaps, los potenciales prestamistas (países “+3”) contarán con un representante formal y, a su vez, se pactaría el acuerdo con una contraparte de la ASEAN (Idem). El peso de los Estados nacionales en el mecanismo de votación se asemeja en gran medida a las IFIs tradicionales. Los aportes de China y Japón son iguales (38.4 mil millones de dólares), no obstante, la República Popular China se divide entre mainland y Hong Kong, que aportará 4.2 mil millones, dejando a Japón como el principal contribuyente y, por consiguiente, mayor decisor (con el $28.41 \%$ de los votos frente a $25.43 \%$ de China mainland). En total, los países añadidos agrupan el $71.59 \%$ de los votos del sistema, mientras que el resto de la ASEAN cuenta con $28.41 \%$ del poder de decisión (ASEAN+3, 2010). El avance de China en el liderazgo regional es significativo en las últimas dos décadas y, particularmente, después de la crisis asiática de 1998 cuando Japón lideró casi unívocamente el rescate regional.

Las disyuntivas políticas discutidas anteriormente y elaboradas por Eichengreen parecieran resolverse con la creación de una estricta Unidad de Supervisión, apoyada por un grupo de investigación independiente y sólidas políticas condicionantes (Rathus, 2010). Como un inicio "modesto", esta canasta de reservas de 120 mil millones de dólares tiene una significación considerable para la regionalización de las finanzas internacionales. El punto central surge de la posibilidad de que China logre localizar al yuan como reserva de valor regional y, progresivamente, hacerlo a nivel global. Su nivel de reservas actual lo hace el principal poseedor de Fondos Soberanos y títulos de valor estadounidenses, por lo que una expansión del yuan tendría una sólida base financiera, así como productiva. El argumento es asumido por Eichengreen (2010) como una importante consecuencia de la actual crisis financiera internacional desatada con el estallido de la burbuja subprime:

El objetivo a largo plazo de China es fortalecer el papel del yuan como moneda internacional, inicialmente como una moneda de reserva regional y, a la postre, como una moneda de reserva global. (Rusia y Brasil han hecho movidas similares para fortalecer sus monedas en sus respectivas regiones). Ésta es la mejor forma de comprender las iniciativas recientes diseñadas para promover a compañías de las provincias del sur de China establecer más transacciones fuera de la frontera denominadas en yuan, así como swaps en moneda local que el gobierno ha negociado con varios socios internacionales. Por supuesto, hacer del yuan una forma atractiva de mantener reservas implica no sólo que el comercio chino se facture y cancele en su propia moneda, sino que también desarrolle profundos y líquidos mercados de valor con títulos denominados en yuan y que su moneda sea convertible en cuenta de capital.

Seguramente, Estados Unidos (y la zona euro) no se habrán esfumado. Esto apunta al desarrollo de un sistema múltiple de reservas no muy distinto al que prevaleció en la primera era de la globalización.

La posibilidad de constituir un sistema de múltiples áreas de reservas, partiendo de una actualidad sólidamente liberalizada y globalizada, no escapa a cuestionamientos 
técnicos y políticos. Sin embargo, las pretensiones de China, Brasil y Rusia que plantea Eichengreen son incuestionables. En el caso suramericano, ya Brasil ha mostrado sus cuestionamientos a la Nueva Arquitectura Financiera regional planteada por Ecuador en el marco de las negociaciones para el Banco del Sur (Rosales, 2010), al tiempo que ha impulsado la constitución del mencionado Banco como una institución para el desarrollo regional que podría ampliar la capacidad de crédito brasileña para profundizar las inversiones de sus empresas en el ámbito suramericano. Por otro lado, ya Brasil estableció junto con Argentina un Sistema de Pagos en Moneda Local (SML) para el comercio de ambos países. La intención del SML es dar solidez a las monedas locales al reducir las trasferencias en dólares y reducir costos para exportadores e importadores.

Un informe del Sistema Económico Latinoamericano y Caribeño (SELA) analiza la iniciativa con optimismo y resume sus primeros resultados: "en sus primeros siete meses de funcionamiento, de octubre de 2008 a abril de 2009, el SML fue utilizado por 160 empresas, por un monto de 122.8 millones de dólares, distribuidos en un total de 214 operaciones”. Además, los datos indican un impulso a las transacciones de pequeña cuantía, por lo que el sistema estaría beneficiando el intercambio comercial de pequeńas y medianas empresas "cerca del $90 \%$ de todas las operaciones fue por montos inferiores a los 500 mil dólares e incluso la mayoría, el 57 \% de las operaciones totales, fue por montos menores a los cien mil dólares" (SELA, 2009). En su mayoría, el intercambio realizado bajo el SML beneficia las exportaciones brasileñas. En 2008, el intercambio comercial de estos dos países rondó los 30 mil millones de dólares (por amplio margen, éste es el intercambio comercial binacional más dinámico de la región), por lo que el volumen de transacciones realizadas bajo el esquema de SML se puede considerar insignificante. No obstante, la evidencia indica que el comercio pequeńo y mediano podría promover nuevas cadenas productivas en moneda local y construir bases para una desvinculación progresiva del dólar estadounidense, una vez que las ventajas económicas de compra-venta con el SML sea aprovechado por grandes empresas.

\section{EL G-20 VS EL G-192. NUEVOS APORTES A LA REFORMA DE LA AFI}

El estallido de la burbuja inmobiliaria y la subsecuente crisis de los subprime llamó una vez más la atención sobre la necesidad de reformar las instituciones y acuerdos que deben regular el sistema financiero global. En este caso, el locus del debate se centró ya no en las IFIs de Bretton Woods como a finales de la década de los noventa del siglo XX, sino en el Grupo de los 20 (G-20), foro de los países más industrializados y las más significativas economías emergentes. Asimismo, la Organización de Naciones Unidas (ONU), de la mano del presidente de la $63^{\circ}$ sesión de la Asamblea General, Miguel D’Escoto, elevó cuestionamientos sobre el carácter poco democrático que implicaba limitar el debate 
al G-20 y la pertinencia de trasladarlo a un eventual “G-192”. De esta forma, un grupo de expertos liderado por el nobel de economía, Joseph Stiglitz, elaboró una serie de propuestas que junto con las políticas defendidas por el G-20 centralizan el debate actual sobre la AFI y su reforma.

Luego del periodo de descrédito que imprimió el conservadurismo anglo-estadounidense a las instituciones de Bretton Woods y la desvinculación de varias economías emergentes hacia sus políticas, préstamos y postulados, la actual crisis ha sido un escenario propicio para su reforzamiento. De hecho, el G-20 ha enfocado el rescate global frente a la crisis desde las instituciones multilaterales. En la reunión de abril de 2009 en Londres, el G-20 acordó reforzar al FMI por medio de la emisión de nuevos Derechos Especiales de Giro (DEG), régimen monetario compensatorio del Fondo), por el orden de 250 mil millones de dólares, así como incrementar el capital de las agencias regionales de desarrollo regional. Esta decisión es una clara muestra del interés de la administración demócrata de Barack Obama de reconstruir la AFI a partir de las instituciones existentes; asimismo, el apoyo de los países emergentes da cuenta de su motivación por formar parte de las decisiones globales y ampliar su margen de acción -y decisión- en las IFIs. Este programa de apoyo se suma a las políticas nacionales de estímulo fiscal (salvatajes generalizados a los capitales en riesgo, nacionalizaciones focalizadas y políticas de intervención sectorial), en una suerte de plan global que lejos de reformar la AFI ha implicado su reforzamiento por primera vez desde inicios del siglo. En especial, estos mecanismos de salvataje podrían reimpulsar la lógica de la financiarización si los capitales ingresan a la circulación del capital en títulos de derivados, en vez de la actividad de la llamada economía real. El acuerdo plantea un impulso al FMI con 750 mil millones de dólares, además de los 250 mil millones en DEGs, unos 100 mil millones para los bancos de desarrollo regional y 250 mil millones en apoyo al comercio. Según el G-20, "junto a las medidas que hemos tomado a nivel nacional, esto constituye un plan global de recuperación en una escala sin precedentes" (G-20, 02/04/09).

En términos de regulación al sistema financiero, los líderes del G-20 acordaron la creación de un Financial Stability Board (FSB) para trabajar en coordinación con el FMI y establecer seguimiento sistemático al sistema financiero y levantar banderas cuando posibles riesgos emerjan. El FSB se aleja de una propuesta "estatutaria" tal y como proponía Krueger con el SDRM, es más bien un acuerdo articulador de las voluntades políticas en el G-20. De esta forma, se mantienen las autoridades y sistemas regulatorios a nivel nacional y el FSB aparece como coordinador (G-20, 02/04/09). Dos aspectos tienen centralidad en la propuesta regulatoria del FSB: por un lado, el establecimiento de sistemas de cuentas comparables y eficientes en el foro político que busca coordinar la economía global; y, por otro, el planteamiento de construir un mecanismo dúctil y efectivo para evaluar y monitorear a las Agencias Clasificadoras de Riesgo (ACR) y, sobre todo, evitar los persistentes problemas de conflicto de interés que contribuyeron a la desinformación -posiblemente nada casual- de los estados financieros de grandes instituciones 
crediticias como Lehman Brothers, IGM y otras que entraron en bancarrota con la crisis financiera de 2008-2009 (G-20, 02/04/09). El monitoreo "sistemático" a las instituciones y mercados financieros se enfoca en los "más importantes fondos mutuales y de pensión".

El fortalecimiento de las IFIs de Bretton Woods se mantiene en reuniones sucesivas, así como los intentos de regulación planteados en Londres, 2009. En la más reciente reunión de Toronto, las agencias de desarrollo regional mantienen un papel protagónico en el otorgamiento de préstamos a los países más pobres (asunto sólidamente cuestionado a comienzos de la década tanto por la Comisión Meltzer como por Anne Krueger) con un incremento en su capitalización por el orden de los 350 mil millones de dólares. Pese a ello, se plantea: "este nuevo capital se suma a los importantes esfuerzos de reforma para hacer estas instituciones más transparentes y efectivas, así como para fortalecer su enfoque en la vida de los pobres, crecimiento económico y la lucha contra el cambio climático y seguridad alimentaria” (G-20, 26-27/06/10). El apoyo de las economías emergentes a estas decisiones tiene como contrapartida un compromiso por parte de la asociación de transformar las cuotas de toma de decisiones "que refleje las nuevas tendencias de la economía mundial". El sistema toma de decisiones de las IFIs basado en cuotas sigue sin ser cuestionado, mientras que abogan por un sistema "trasparente y meritocrático" para escoger a las autoridades de estas instituciones.

Por otro lado, las propuestas de la Comisión de Expertos de la ONU (2009) enfatizan una crítica institucional que propugna debates más democráticos bajo el marco de un G-192. En este caso, la Comisión defiende una reforma, no sólo en términos de gobernanza de las IFIs sino también de su concepción y las políticas que defienden. En el caso de las acciones tomadas por el G-20, la Comisión plantea críticas sólidas, como por ejemplo, al FSB: "hacer cambios marginales a la estructura regulatoria no aminorará la situación actual ni prevendrá crisis futuras. Reformas más profundas en el FSB deben, consecuentemente, asumir sus deficiencias en gobernanza, mandato y perspectivas económicas".

De alguna forma, se propone el regreso al sistema de promoción de pleno empleo y estabilidad monetaria planteado en la posguerra. A las existentes instituciones se suma una instancia global denominada Consejo Global de Coordinación Económica, ubicada a nivel de la ONU y encargada de coordinar acciones en materia económica sobre la base de una toma de decisiones democrática e inspirada en el trabajo de un "panel de expertos" encargado de elevar propuestas.

$\mathrm{Al}$ mismo tiempo, avanza ideas de reformas moderadamente más contundentes que aquéllas defendidas por el G-20. En primer término, se plantea el establecimiento progresivo de un Sistema Global de Reservas (SGR o Global Reserve System) con el propósito de proveer estabilidad al sistema financiero global, un sistema cuyo antecedente histórico más importante data de la propuesta de John M. Keynes en el marco de la Conferencia de Bretton Woods. Este mecanismo puede surgir de los actuales DEGs bajo 
el auspicio del FMI o de una nueva institucionalidad global. El informe expone el carácter limitado de los actuales DEG:

Cuando los DEGs fueron creados, se esperaba que se convertirían en un mayor componente de las reservas globales, creando así un sistema en el cual el crecimiento de la liquidez global dependería en decisiones internacionales deliberadas. Esta expectativa no fue satisfecha, y un total de 21.1 mil millones de DEGs se emitieron en dos periodos (1970-72 y 1979-81), lo que representa sólo una fracción mínima de las actuales reservas mundiales (traducción propia, UN Expert Commission, 2009).

No obstante, la adopción de un SGR debe responder a un proceso progresivo que incluye, según la comisión de expertos, una transición con sistemas regionales de reserva:

Si un grupo suficientemente grande de países acuerdan juntar sus reservas en un sistema acordado para crear y mantener una moneda de reserva común, del cual estarían dispuestos a intercambiar por sus propias monedas, una reserva regional -o incluso un sistema de casi cobertura global- podría establecerse sin el acuerdo de todos los países (traducción propia, $U N$ Expert Commission, 2009).

La Comisión reconoce que la ICM de la ASEAN+3 es un ejemplo tangible de acuerdo multilateral de swaps que podría evolucionar hacia un sistema regional de reservas. La propuesta evoluciona hacia un régimen descentralizado en el cual el FMI u otra instancia global podría coordinar los sistemas regionales de reserva, proveyendo mecanismos regionales de solución de crisis y elevando el poder de decisión de los pequeños países en sus regiones (UN Expert Commission, 2009). Esta visión coincide con la planteada anteriormente por Eichengreen y que dejaría a China, Brasil, Rusia e India como nuevos actores de poder regional en el ámbito monetario, pero también productivo y comercial.

Un asunto que la Comisión enfrenta con claridad propositiva es el de renegociación de deudas soberanas. En este caso es crítica frente al actual sistema y a las CACs, defendidas por los principales actores privados del mundo financiero. Nuevamente, la Comisión propone un modelo "estatutario", muy similar al SDRM. Pocos rasgos diferencian la propuesta planteada por la Comisión de la ya discutida a comienzos de la década por Anne Krueger ya que estimula la cooperación y resolución del conflicto a las partes, pero a la vez provee un sistema ordenado y predecible tanto para el soberano como para los acreedores. Sin embargo, la Corte Internacional de Reestructuración de Deuda sería un mecanismo legal que, a diferencia del SDRM, debería surgir de una institucionalidad nueva dados los conflictos de interés que sugiere erigir tal mecanismo de los cimientos del propio FMI, siendo esta una institución sujeta a presiones por parte de los mayores acreedores y siendo, además, un importante acreedor en sí mismo (UN Expert Commission, 2009). 
Antulio Rosales

\title{
REFLEXIONES FINALES: LA LUCHA (POR Y) CONTRA LA ESPECULACIÓN, UNA HISTORIA SIN FIN
}

\begin{abstract}
Cuando me dicen que la crisis marcará un cambio fundamental en la estructura y el manejo de la economía mundial, me acuerdo del huracán Katrina. Al demostrarse el grado de la desigualdad en Estados Unidos, y también la incapacidad de respuesta de su sector público, Katrina, se dijo, marcaría un cambio fundamental en la política social y el papel del gobierno en Estados Unidos. Pero no pasó mucho tiempo para que Estados Unidos se relajara sobre sus cómodas viejas formas. Análogamente, surge la pregunta si una vez que pase la crisis, todo volverá a la normalidad.

Barry Eichengreen (2010) traducción propia.
\end{abstract}

Después de la muy mediática crisis financiera entre 2007 y 2009, cuando la economía global empezaba apenas a recuperarse tímidamente de la recesión, en los primeros meses del año 2010, el mundo asiste a una nueva crisis. Esta vez, un Estado soberano semi-periférico de Europa enfrentó la amenaza de una corrida especulativa que ponía en jaque su estabilidad. Con la crisis de Grecia, suena una campanada sobre las consecuencias posibles que implicaría, como dice Eichengreen, "volver a la normalidad". Este panorama, similar al de otros países europeos y del llamado tercer mundo, renueva las preguntas sobre la pertinencia de establecer un sistema ordenado o estatutario de reestructuración de deuda. A su vez, son reiterados los llamados de algunas organizaciones sociales de norte y sur para establecer mecanismos globales como la Tasa Tobin que contribuya a reducir el volumen de movilización de capitales especulativos. Aún está ausente de la agenda la re-vinculación de las finanzas a la economía real, que incorpore una visión de justicia social y ambiental.

En efecto, las propuestas de transformación global de la AFI se enfrentan a serios obstáculos de acción colectiva que precisamente detiene a los Estados frente a la amenaza constante de la salida apresurada de capitales o un "castigo" del mercado y sus principales agentes. Los Estados han invertido ingentes recursos como "estímulos fiscales" para salir de las crisis en la última década, pero en realidad han socializado las pérdidas y han salvado a poderosos actores del propio capital financiero que estarían facilitando la oxigenación del mercado de derivados. Sin duda, éste es un tema central para la reconfiguración de la AFI. Autores como Wray (2009) promueven la prohibición del mercado de derivados que saca del balance de los bancos regulados y protegidos compromisos que superan en gran medida sus activos. Por su parte, Guillén (2009) plantea que

El gusto por una separación entre la toma de riesgo y la asunción de su carga quedó tan bien enraizado, que no es posible considerar el retorno a una reintermediación financiera que significaría regresar a los bancos de antaño. Sin embargo, la titularización debe salir de un 
universo desreglamentado y ser supervisada por las autoridades de regulación bancaria para sanearla y simplificarla”.

El cabildeo financiero representa el principal obstáculo hacia mayores regulaciones, limitando considerablemente los debates acerca de la reforma de la AFI.

Dos procesos circundantes - a veces articulados y otras veces contradictorios- parecieran cobrar mayor fuerza en el contexto del fin de la primera década del siglo. Por un lado, el G-20, en cuyo seno se articulan los intereses de los principales Estados industrializados y los de las mayores economías emergentes, otorga nuevos aires a las IFIs existentes y deja de lado viejos cuestionamientos sobre su gobernanza. Este fortalecimiento viene acompańado de una expresa voluntad por mejorar sus patrones de eficiencia y reorganizar el sistema de toma de decisiones para "reflejar" la nueva realidad económica mundial y a cambio dar estabilidad al sistema financiero y productivo de la globalización. Así se cumple un proyecto central para los gobiernos como el de Estados Unidos, en la medida en que China y otros países emergentes son acreedores importantes de sus deudas. Para las economías emergentes, por su parte, mayor participación de toma de decisiones en las IFIs representa un paso significativo en su establecimiento como potencias de interés geopolítico, al ser estas instituciones las que determinan las principales líneas de crédito para obras de desarrollo (asunto de gran interés para las emergentes empresas trasnacionales de estos países) y las que establecen los principios de condicionalidad, préstamo y coordinación de política económica nacional.

Por otro lado, se van gestando de manera progresiva, mecanismos de regionalización financiera, cuyo ejemplo más exitoso es sin duda el mecanismo de ICM propuesto por la ASEAN+3, iniciativa que precisamente surgió con los debates que provocó la anterior gran crisis financiera, a finales del siglo Xx en el sureste asiático. El camino hacia el establecimiento de mecanismos regionales de reserva en el Golfo Pérsico, Suramérica y área de influencia rusa comienza a prefigurarse con significativos tropiezos pero también algunos logros. En este caso, el frecuente avance de la dialéctica financiarización-crisis financieras pareciera estar dejando a viejos poderes imperiales atrás y solidificando nuevos actores que en las escenas subregionales estarían llamados a reemplazar a los primeros. Las economías emergentes estarían beneficiándose de este proceso al estar simultáneamente incorporándose como miembros privilegiados del sistema financiero global y, a su vez, comenzar a gestar nuevas áreas de influencia monetaria, productiva y comercial en sus respectivas regiones. A pesar de la participación de nuevos actores en los mecanismos de la AFI y su posible reforma, las dinámicas de la globalización financiera permanecen poco alteradas. 


\section{BIBLIOGRAFÍA}

ASEAN, "The Joint Ministerial Statement of The 13th ASEAN+3 Finance Ministers' Meeting", disponible en: http://www.asean.org/documents/JMS_13th_AFMM+3. pdf, consultado el 20 de mayo de 2010.

Banco Internacional de Pagos, estadísticas de derivados, disponible en: http://www.bis. org/statistics/derstats.htm, consultado el 28 de septiembre de 2010.

Banco Mundial, World Bank Data, disponible en: http://data.bls.gov/PDQ/servlet/ SurveyOutputServlet?data_tool=latest_numbers\&series_id=LNS14000000, consultado el 25 de septiembre de 2010.

Bleger, Leonardo, "Actual etapa de la globalización financiera: las hipotecas en EEUU y su impacto mundial", En curso virtual: El sistema financiero internacionaly América Latina, Programa Latinoamericano de Educación a Distancia, Buenos Aires, 2009.

Eichengreen, Barry, "Crisis Resolution: Why We Need a Krueger-Like Process to Obtain a Taylor-Like Result", Institute for International Economics Conference on Sovereign Debt Workouts: Hopes and Hazards, 29 de abril 2002, disponible en: http:// www.econ.berkeley.edu/ - eichengr/policy/iiekrueger.pdf, consultado el 15 de mayo de 2010 .

, "Lessons of the Crisis for Emerging Markets". International Economic Policy, Volumen 7, 2010, pp. 49-62.

G-20, "The Global Plan for Recovery and Reform", 20 de abril de 2009, Disponible en http://www.g20.org/Documents/final-communique.pdf, consultado el 06 de junio de 2010 .

“The G-20 Toronto summit declaration”, 26-27 de junio de 2010, disponible en: http://www.g20.org/Documents/g20_declaration_en.pdf, consultado el 28 de junio de 2010.

Grabel, Ilene. "International Private Capital Flows and Developing Countries". En: HaJoon Chang, Rethinking Development Economics. Anthem Press, 2003, UK.

Guillén, Héctor, "La crisis financiera de los préstamos subprime", Comercio Exterior, vol. 59, núm. 12, diciembre de 2009, pp. 947-969.

Held, David; Anthony McGrew; David Goldblatt; Jonathan Perraton, Transformaciones Globales: Politica, economía y cultura, Londres, Oxford University Press, 2002.

Helleiner, Eric, "The mistery of the Missing Sovereign Debt Restructruring Mechanism", Contributions to Political Economy, (27), 2008, pp. 91-113.

Meltzer Report, "International Financial Institutions Advisory Commission”, 2000, disponible en www.house.gov/jec/imf/meltzer.htm, consultado el 15 de mayo de 2010.

Nersisya, Yeva y Wray, Randall, "The Global Financial Crisis and the Shift to Shadow Banking”, Working paper No 587, Febrero 2010, Levy Economics Institute, disponible en: http://www.levyinstitute.org/pubs/wp_587.pdf, consultado el 24 de septiembre de 2010. 
Krueger, Anne, "A New Approach to Sovereign Debt Restructuring", 2001, disponible en: http://imf.org/external/np/speeches/2001/122001.htm, consultado el 20 de abril de 2010.

, A New Approach to Sovereign Debt Restructuring. International Monetary Fund, Washington, DC, 2002.

Rathus, Joel, “The Chiang Mai Initiative's Multilateralisation: A good start”, East Asia Forum, 23 de mayo de 2010, disponible en: http://www.eastasiaforum. org/2010/03/23/the-chiang-mai-initiatives-multilateralisation-a-good-start/, consultado el 6 de junio de 2010.

Rosales, Antulio, "El Banco del Sur y el sucre: (des)Acuerdos sobre una Arquitectura Financiera Alternativa”, Trabajo presentado en las Jornadas de Economía Crítica, Zaragoza, España, febrero 2010.

Salama, Pierre, "La crisis financiera del sistema financiero internacional", Programa Latinoamericano de Educación a Distancia, Buenos Aires, 2008.

Sevares, Julio, El imperio de las finanzas, Grupo Editorial Norma, Buenos Aires, 2005.

Stiglitz, Joseph, El malestar en la globalización, Taurus, Bogotá, 2003.

Sweezy, Paul, "The Triumph of Financial Capital". The Monthly Review, 1994, disponible en: http://www.monthlyreview.org/940600sweezy.php, consultado el 12 de junio de 2010.

SELA, "Experiencias de Cooperación Monetaria y Financiera en América Latina y el Caribe. Balance Crítico y Propuestas de Acción de Alcance Regional”, 2010, disponible en: http://www.sela.org/DB/ricsela/EDocs/SRed/2010/03/T023600003766-0 -Experiencias_de_Cooperación_Monetaria_y_Financiera_en_ALC2.pdf, consultado el 14 de mayo de 2010.

Toussaint, Eric, Diferencias entre las crisis de 1983 y 2007-2008. En curso virtual: "El sistema financiero internacional y América Latina”, Programa Latinoamericano de Educación a Distancia, Centro Cultural de la Cooperación, Buenos Aires, 2009.

Ugarteche, Oscar, "La unidad monetaria sudamericana: elementos para el diseño", 2008, disponible en www.obela.org/.../LA+UNIDAD+MONETARIA+SUDAMERICANA. doc, consultado el 10/05/10.

UN Commission of Experts, "Report of the Commission of Experts of the President of the United Nations General Assembly on Reforms of the International Monetary and Financial System", United Nations, 2009, disponible en: http://www.un.org/ ga/econcrisissummit/docs/FinalReport_CoE.pdf, consultado el 25 de mayo de 2010.

Vanoli, Alejandro, Crisis subprime y crisis financiera global, En curso virtual: "El sistema financiero internacional y América Latina”, Programa Latinoamericano de Educación a Distancia, Buenos Aires, 2009.

Wray, Randall, "Money Manager Capitalism and the Global Financial Crisis", Septiempre 2009, Levy Economics Institute, disponible en: http://www.levyinstitute.org/pubs/wp_578.pdf, consultado el 25 de septiembre de 2010. 
